\title{
THE DEVELOPMENT OF THE PLAN OF THE THERSILION.
}

Mr. Benson in the preceding paper has given an account of the new facts which have been brought to light by the complete clearing of the Thersilion. With regard to these points of fact there can be no question and in the deductions to be drawn from them we are for the most part agreed. It remains to be seen whether from the remains before us we can reconstruct a building of any known Greek design, in other words, whether we can discover what was the builder's plan and how he developed it. At first sight a large columned hall of this nature appears to be un-Greek in character: the only parallel we can produce for it is the late Hall of the Mysteries at Eleusis, which however only resembles it in the bx adest characteristics. Where we do find halls which resemble this building however is in the East. The Hall of the hundred columns at Persepolis (Perrot et Chipiez, v. p. 723) presents several striking analogies: like the Thersilion it is a large square building on one side flanked by a portico while we have two doors on each of the other three. Now, as is clearly shown by the character of the building, the Thersilion belongs, in its original plan, to the earliest period after the foundation of Megalopolis by Epameinondas. That is sufficiently proved by the -1 cramps and the use of tufa rather than conglomerate for the foundation bases. Moreover just at this period we have a direct communication between Persia and Megalopolis in the person of Antiochus, who visited Susa as a delegate from the Arcadian league in 367 B.c. (Xen. Hell. vii. 1, 33-38 J.H.S. Supp. Pap. I. p. 128), and it is quite possible, whether he was the dedicator of the theatre thrones or not, that he brought back the idea of such a columned hall from the East. But it can have been only the general idea that was so brought to Megalopolis : the arrangement of the columns in the Thersilion is entirely different from that of its prototypes in the East, while the inward slope of the floor is also a new element. Thus, though this building may have owed its origin and shape to the East, its plan, as I will endeavour to show, is taken from a common Greek type, and is in fact simply that of a Greek theatre.

Mr. Gardner has already remarked that the Thersilion in its arrangement 'somewhat resembled a theatre' (Megalopolis, p. 70), and Dr. Dörpfeld has called it a 'theaterähnlicher Bau' (Mit. xvii. p. 98). These remarks however were based more on the general design of the building falling to the centre than on any detailed analysis of the plan. This general view of 
the design receives strong confirmation from the discovery of the relative heights of the column bases behind the centre. All the column bases on the line lettered $A B C D$ of our plan (Pl.XXI.) are of equal height, the height that is of the bases of the third row of columns. Thus the rise to the outer row stops on each side of the building at the lines marked $E F$ and $G H$. We have then a quadrangular building rising, roughly speaking, on three of its sides, while along the fourth we have a façade of columns returning at either end, so that between the lines $A B, C D$ and the lines $E F, G H$ are formed two passages between the rising and the level parts of the building, and these passages cannot have been higher than the line $A B C D$. How

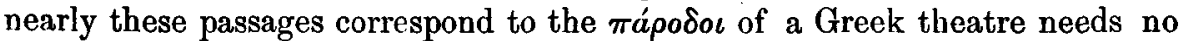
further emphasis. And it is equally obvious that the line of columns $B C$ takes exactly the place of the frons scenae of a Greek theatre. Under this supposition the space behind $B C$ bears exactly the same relation to the Thersilion as the great portico does to the theatre. This will appear still more plainly when we come to deal with the geometrical development of the plan. At present it will suffice to point out that the difference in level between the centre columns of the building and those of the line $B C$ is $2 \mathrm{ft}$. 6in., and the distance between them being too small to admit of so steep a slope we are driver 'o suppose either three steps or a sudden drop in front of $B C$ corresponding to the steps in front of the great portico.

Passing however from these points of general resemblance to a theatre we must, next examine the plan more in detail. The first difficulty which meets us is how the builder adapted the circular plan of a Greek theatre to the quadrangular building and the question arises whether we can trace any circular plan in the Thersilion. This question will be best answered by an application of the canon of Vitruvius (v. 7). The following is a paraphrase of this passage, as I understand it. 'First in the lowest circle describe three squares with angles equidistant. Let that side of the square which is nearest to the scena form the front line of the proscenium. Next draw a tangent to the circle parallel to this line: this will be the front line of the scena. Draw a diameter of the orchestra parallel to the line of the proscenium and at its extremities where it cuts the circle (of the orchestra) take centres and with the diameter as radius draw two more circles, that described with the right hand centre limiting the proscenium on the right with the left hand on the left.' 1 This is all that concerns us for the present. The first question which presents itself is: Are the ima circinatio and the orchestra the same? and, if not, what is their relation to one another? Most writers nowadays identify them, an identification which leads us on to the startling paradox that in a Greek theatre one-seventh of the circle is cut off from the orchestra for the proscenium (v. Megalopolis, p. 77). Moreover in this interpretation lies all the difficulty which has led to the alteration of the reading and very many extraordinary translations of the Latin. Again Vitruvius seems to

\footnotetext{
1 Here I follow the reading of the MSS. as against that of Rose and Müller-Stribing, and

H.S. - VOL. XIII.

others (v. J.H.S. xii. p. 360 ). 


\section{THE DEVELOPMENT OF THE PLAN OF THE THERSILION.}

me to have sufficiently guarded against this misconstruction, when he speaks of the Roman Theatre (v. 6) : et ab eo loco per centrum parallelos linea ducatur quae disjungat proscaenii pulpitum et orchestrae regionem. Here he distinctly speaks of the orchestra as being a definite part of the ima circinatio; and it is to me inconceivable that in the very next chapter he should identify the two. Nor again can Vitruvius' orchestra be the remaining six-sevenths of the ima circinatio for the simple reason that the orchestra in a Greek theatre does not begin immediately at the bottom row of seats, whereas it is obviously a circle and has a centre. Vitruvius here is certainly quoting from some Greek authority and for Greek

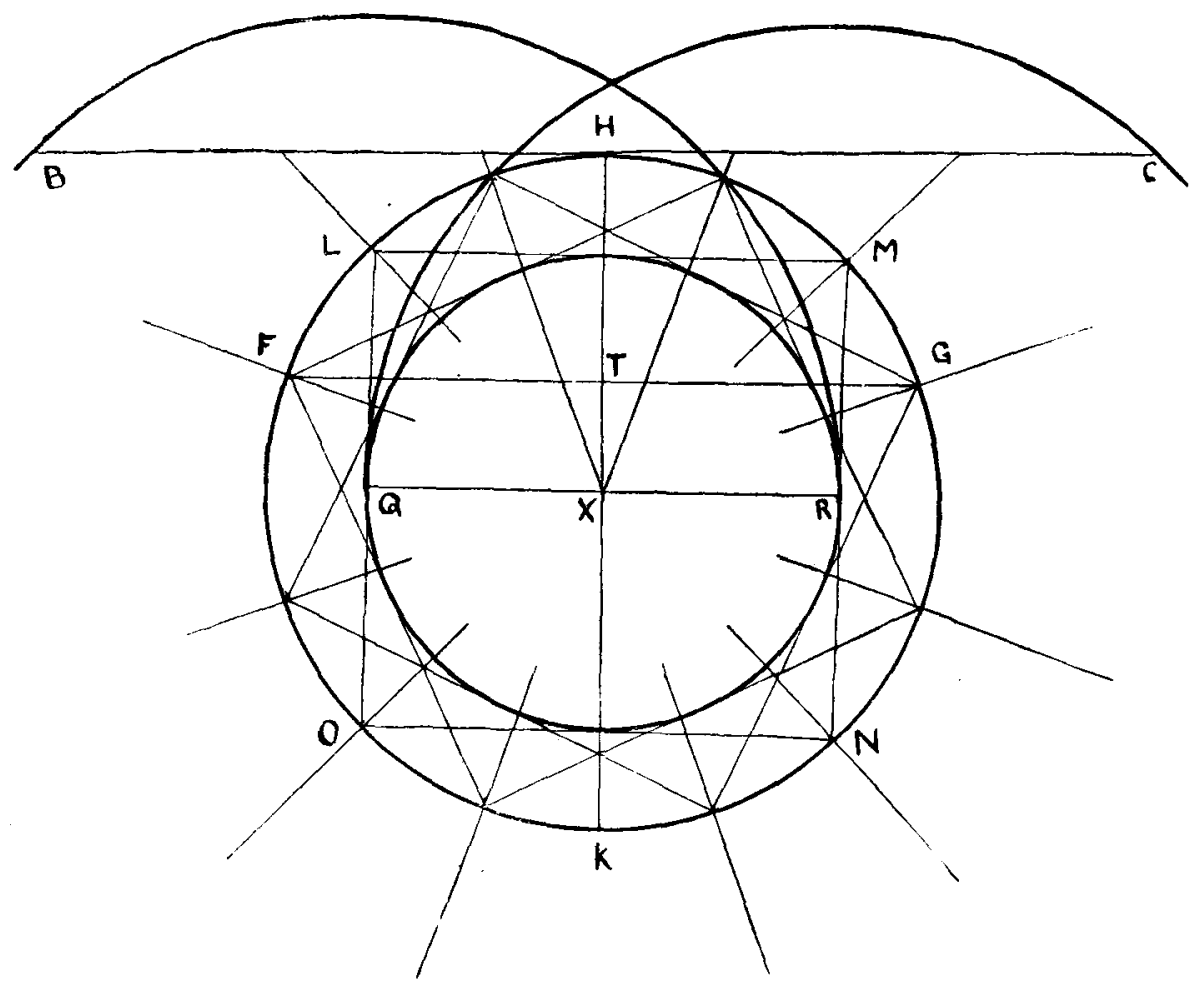

readers it was unnecessary to say in so many words that the orchestra was a circle concentric with the ima circinatio. ${ }^{2}$ What then I take to be the orchestra according to Vitruvius is contained in a circle inscribed in the square one line of which bounds the proscenium. As the diameter in the Roman theatre separates proscenium from orchestra, so it is with the side of the square in the Greek theatre. Whether the proscenium was

2 Here it is obvious that in most Greek theatres only the semicircle opposite the scena is an arc of the ima circinatio, but theoretically, according to Vitruvius, the whole of the block of seats forms the arc of a circle. 
raised in any way above the level of the orchestra is a question which need not be touched on here. The word means simply the part of the building before the scena, and it makes no difference to our plan whether it was raised or not.

To apply this canon however to the Thersilion. Take the centre $X$ and with a radius of 32 Greek feet, ${ }^{3}$ describe the circle which we may roughly call $F G K$. This circle just touches all the top bases of the fourth row except the corner ones and also the line $B C$ is a tangent to the circle. In this circle describe the square $L M N O$ of which the side $L M$ is parallel to $B C$. Within the square describe a circle $P Q R$ and draw a diameter $Q R$ parallel to $B C$ and $L M$. From centre $Q$ at distance $Q R$ and from centre $R$ at distance $R Q$ describe circles. These, as will be seen by reference to the plan, fall just outside the points $B$ and $C$ respectively. The inner circle also, as will be seen on the plan, falls just outside the four centre columns.

Here I have endeavoured to carry out exactly the instructions of Vitruvius, and the result is striking enough. Taking the ima circinatio to be bounded by the fourth row of columns, the orchestra circle falls just outside the central four; the scena is a tangent to the ima circinatio, and both scena and proscenium are limited at the sides exactly in accordance with the law of Vitruvius.

Before I pass on to discuss the levels of the various parts of the building, there is still another instruction of Vitruvius to be dealt with. 'The staircases,' he says, 'are to be set at the angles of the three squares, and their number is to be doubled half way up.' Now in the Thersilion the rows of columns backed by the doors take the place of the staircases: both are lines useless for spectatorial purposes. But it is manifestly impossible in a rectangular building like the Thersilion to arrange the lines of columns exactly according to the rules of Vitruvius; for thus the intercolumniations at the corners being further from the centre would be greater than those in the middle of the same line. The architect's solution in this case was both simple and ingenious. Take $H K$ diameter of the ima circinatio at right angles to $B C$ or the scena : and from this cut off a third part $H T$. Through $T$ draw a line parallel to $B C$. That line is $G T F$. Then in the circle describe two other squares with angles at $G$ and $F$ respectively. The angles of these squares together with those of the former square LMNO point exactly the lines of columns both in the auditorium and in the scena. Half way up originally in the second row but later in the third intermediate columns were added.

But it may be fairly asked: Where is any evidence for all these circles? The plan of the building is simply rectangular, and there is no necessity for the introduction of all these complications. It is a matter of cumulative evidence. In the first place it will not, I think, be questioned that the

\footnotetext{
3 Here I adopt a Megalopolitan foot of 308 m., which is that shown by Mr. E. A. Gardner
}

to have been the unit of measure used in the construction of this building. 


\section{THE DEVELOPMENT OF THE PLAN OF THE THERSILION.}

original builder modelled the general scheme of his building on a theatre plan, and, the Greek theatre being planned on a circular scheme, it was almost impossible to do without the use of circles in its adaptation to a rectangular building. Secondly it has been shown with what exactitude the circular planning gives the position of almost every column in the building. In the third place we have to do with levels. A full discussion of the slope of the building is impossible for any but a trained architect, but there is one point which seems to me to point to a circular rising. Obviously in that case the corner bases of the various rows lying further away from the centre would necessarily be somewhat higher than the other bases of the same line, and this is exactly what we find to be the case. The corner bases of the fourth row lie $2 \frac{1}{2}$ inches higher than the other bases in the line: those of the third row 6 inches higher; while in the second row the top bases at present in position are of tufa and so were certainly not meant to be seen at all. Though they are formed of a single block smaller than the double course under them, they probably supported another white limestone basis on the top, as a similar basis of one block is that of $a 1$. Allowing for a top basis 10 inches deep these bases would be $8 \frac{1}{2}$ inches above their line. In the outermost row all the top bases are lost, so that it is impossible to calculate their original relative heights. I do not intend to enter into the question as to whether there was a regular series of steps on the floor or whether it was a simple slope. My point is that the rise whatever it was cannot have been simply rectangular, as then the corner bases must have been on a level with the others of their line.

We next have to deal with a subject already touched on by Mr. Benson, namely that of the roofing of the building.

Here at first $I$ will give a list of the tile-inscriptions found in the Thersilion.

(1) $\triangle$ AMOCIOIAPXINOY (Megalopolis, p. 140, Nos. 6 and 9). Many additional fragments bearing the same inscription, or with the order of the words inverted, have been found during the last two seasons.

(2) (a) 三ПАГWTIMOMA

(B) UTIMOMA $\quad$ ABIB

( $\gamma$ ) MOMA (Megalopolis, p. 140).

(3) OCIOITETAPTOY

(4) TАГ $\Omega$

TIAMO

$A$ in a circular stamp.

(6) APICITAN

4 This much, however, may be said. The layer of white chips mentioned by Mr. Benson as lying under the tile layer (not above it, as Mr. Schultz says, Megalopolis, p. 20), if not in itself a paving, at any rate gives us a floor level, and that is a simple slope. It may indeed be an actual paving, as it is some two inches thick, and is spread in a regular layer over nearly all the building. 
The last almost certainly has come originally from the stoa Aristandreios across the river. The latter part of $2 \beta$ and 5 are certainly numerals. Of the remainder No. 1 is simple. 'The public tile-works (or public tiles) managed by (or in the year of office of) Archinus.' Of Archinus we know nothing.

No. 2 is harder. Perhaps the unshortened inscription would be '́t

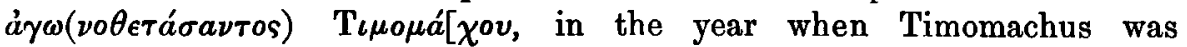

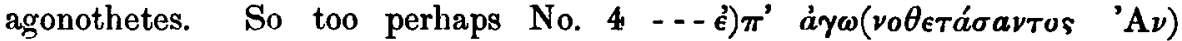

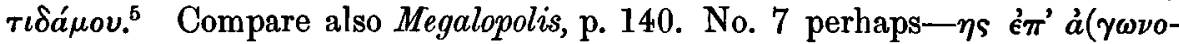

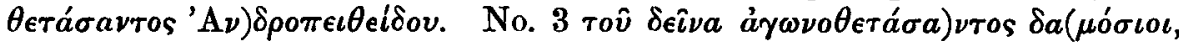

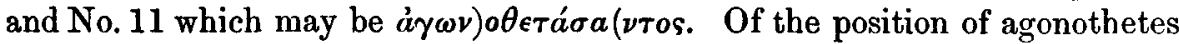
at Megalopolis we know nothing: but from the fact that Antiochus held the office at the time of his dedication of the thrones of the theatre, it is certain that it was one of the most honourable in the town. Cf. also Megalopolis Inss. Nos. IX. and XXVI.

Finally we have No. 3. This may either mean 'public tiles from the fourth factory' or 'of the fourth tier of roofing.' This tile was found between the third and fourth rows of columns, over which would be the fourth tier of roofing if we suppose a roof sloping inwards to the centre from the wall, with lights between the roofs over each line of columns. This arrangement would moreover give light in every portion of the building. The objections to this however are twofold: in the first place, as Mr. Benson has pointed out, the water would drain off into the centre of the building: and secondly there is the structural difficulty; for there would be a danger that the inward thrust of the roof would be too great for the columns to bear. ${ }^{6}$ Some such principle as this however was, I believe, the original one in the Thersilion: nor originally was the entire building roofed over. Here however of course our tile inscription can give us no evidence as it is of a much later date. A glance at the building will show three spaces which were likely on the original plan to have remained unroofed. In the first place there is the space between the 'orchestra' circle and the ima circinatio, and secondly there are the two passages leading into this, which correspond to the parodoi in a Greek theatre. Now I am quite at one with Mr. Benson in his argument as to the later roof of the building, when the intermediate columns of row $c$ were added; but I cannot believe than the original builder would have placed a clerestory over an architrave with a span of 34 feet, which is that of the third row of columns before this addition. ${ }^{7}$ From our consideration of the original design we have to eliminate altogether the later

5 Mr. Richards (Megalopolis, p. 141) shows that the $\Delta$ form is simply a Megalopolitan $\Delta$ but in this inscription in order to read at all it must $=\Delta A$.

- Mr. Schultz, however, informs me that 'there would have been no danger from the thrust inwards if the roof principals were proporly constructed and tied in... The load could easily be made to bear vertically on the columus.' 7 It is true, as has been pointed out to me by Mr. Schultz, that these pillars carried wood beams or framed wooden girders, and so even with this span might have carried a great weight. But at the same time this, so far from being the strongest, is the weakest point in the building, and could never have been chosen to support a clerestory. 
bases. We must then look for some other system; but before entering further into the question we must see if there are no other parts of the building which were later additions and did not belong to the original plan. There are, I think, two such additions. Of these the first has been already recognized, namely, the wall dividing the portico from the interior of the building. Originally there was a simple line of four columns behind the portico. But there was also another alteration made in the building which had something of the same character. It will at once be observed on our plan, that the passages or mápodor, unlike those in a Greek theatre, lead into blank walls. But this was not the case originally. It is only in the south-east corner of the building that we have any remains sufficient to draw conclusions from. But here we can, I think, say definitely that the part of the east wall between the south-east doorway and the south wall, together with the doorway itself, is not part of the original building. Our evidence for this again is cumulative but, I think, none the less sound. In the first place we have to do with the character of the masonry. As has been seen, the level of the column in the south-east corner of the building is not that of the rest of the outer row, but lower, coursing with the columns of the third row and with all those of the line $A B C D$. Nor can it be doubted that an architrave ran over it crossing from $B$ to the corner of the building. From this it is evident that the level of the floor immediately in front of this line cannot have been set at the higher level of the outermost row of bases, but must have been at that of the line $A B$. We should have expected then along the piece of the east wall under discussion to have found a row of orthostatae similar to those of the adjoining south wall. None such exist however on the inner face of the wall, which is built of some of the smallest blocks used in the building. On the outer side indeed orthostatae are used but they are not of the same size as those of the south wall, being much thinner (v. Megalopolis, p. 22, Fig. 6). A glance at this same figure will also show that the two walls are not properly bonded together. The large outside corner block has simply been notched into to admit the inner block of the east wall. Probably originally its north face overlapped the unworked portion of the orthostatae block next to it. The fact that many of the half-cramp marks in this part of the building have no corresponding marks on other stones is sufficient evidence in itself that some radical alteration has been made from the first design.

Secondly the doorway $A$ in Mr. Schultz's plan is different from all the other doorways in the building, being some two feet narrower (Megalopolis, p. 22). It is true that the reason for this may be that there would not be so many people entering and leaving by this door as by the others. These other doors come in the middle of the raised auditorium, whereas this comes at the end. Still I cannot believe that the original builder would not have made all the doors identical.

Thirdly if we suppose a break in the wall between the south-east corner and the point $E$ on our plan, we are met at once by a number of coincidences. In the first place the anta so formed at the point $E$ is exactly in 
line with the column row $B C$. And hence it follows that the bearing of an architrave from this point to the south-east corner is equal to that from the line $B C$ to the columns separating the hall from the portico : and this again is equal to the intercolumniations along the outermost row of columns. It is the greatest bearing of any architrave in the building, except that of the original third row, averaging $28 \mathrm{ft} .10 \mathrm{in}$. English measurement. ${ }^{8}$

I would suggest then that whether it was roofed over or not these parodoi were originally, as in a Greek theatre, open at the ends and formed probably the principal entrance into the building. ${ }^{9}$ To return however to the question of roofing, which is not directly affected by these alterations; I do not see the impossibility of a roof sloping to the centre in the original design. This roof would end after the fourth column row while there may well have been a separate roof supported by the four central columns over the 'orchestra' circle. This arrangement would bring all the water of the building into the space between the ima circinatio and the orchestra; and supposing the plan to be modelled on that of a theatre this space just corresponds to the óxerós. It is true that no remains of any water channel have been discovered there; but as after the alterations the whole hall was undoubtedly roofed over, the arrangements for the water being no longer needed would naturally be removed.

Such then I take it was the adaptation of the theatre plan to a roofed rectangular hall built in the first half of the fourth century B.c.: and I think the evidence that the plan is that of a theatre is too strong to be overthrown entirely.

Only one other point arises. Supposing that the Thersilion is built as a theatre, does this throw any light on the stage question? Only negatively: it is obvious that the speaker stood in the lowest orchestra circle, not on any raised pulpitum. Probably the raised part behind $B C$ was used for the seats of the committee or $\delta a \mu \iota o p$ oi or whatever committee corresponded to that body in the earliest years of the league.

I am very much indebted to Mr. Schultz, for reading this paper through and offering many criticisms and suggestions, many of which are embodied in the paper, while others are added as footnotes.

\section{Other Minor Discoveries at Megalopolis.}

ON other sites at Megalopolis few finds of any value were made last spring. The most important of our discoveries necessitates a correction of

\footnotetext{
8 It is true, as Mr. Schultz has reminded me, that the architrave here must have been of stone and not of wood, as in the interior building. But such a large gateway would naturally be divided by one or more central piers, just as in the case of the entrance from the theatre side; thus there would be no necessity for any
}

long bearing, while none of the symmetrical effect gained by the correspondence in width between the parodos and scena would be lost.

${ }^{9} \mathrm{Mr}$. E. A. Gardner has suggested to me that the cill course in these parts of the walls is probably original and formed the tread to gateways at the end of the parodoi. 
Mr. Schultz's plan of the Stoa Philippeios (Megalopolis, Pl. XV.). In each of the projecting wings of this building only one internal row of columns is there marked, which gives a very irregular appearance to these parts of the structure. Acting on a suggestion offered to us by Dr. Dörpfeld on the occasion of his visit to Megalopolis, we made a digging to see whether there had not been a second row. This we found to be the case. This second row is the same distance from the inner returns of the wings and the two internal columns carrying on that return, that the other row is from the outer wall and anta (i.e. $17 \mathrm{ft}$.), the middle intercolumniation from centre to centre of the columns thus being $14 \mathrm{ft}$. Thus the plan of these wings, independently of the rest of the building, is that of an enneastyle façade covering a hall divided by two rows of three columns into three aisles, of which the middle one is the narrowest. The intercolumniation of the two internal rows covers two of the façade, the two side aisles three.

At the S.W. end of the Stoa Philippeios, and south of the building numbered 26 on Mr. Loring's Plan of Megalopolis (Megalopolis, Pl. I.), we discovered remains of a columned building of rather late date, which, like that figured on the plan, probably formed part of the gymnasium. In one corner of the building, set between two column bases, was a well from which a line of water pipes ran for some distance towards the river. There is much late building over the site; but there are also some remains of a good conglomerate wall carrying on the line from the corner of the Philippeios Stoa towards the river. The column bases are of the usual white limestone, but they have no lower bases under them, and they all have the two late lead-run dowel holes.

To the south of this building, in the part marked 'Tempelbezirk der grossen Göttinnen' on Curtius' Plan (reproduced in Megalopolis, p. 102), we made some experimental diggings; but, beyond a network of Byzantine walls and a tile waterpipe similar to that leading into the temenos of Zeus Soter, nothing was found. One of these tiles bore the inscription

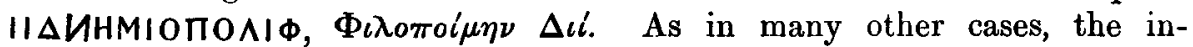
scription was written forwards on the stamp, and so reads backwards on the tile. There is nothing in the inscription to prevent our attributing it to the great Philopoemen. Probably this water ran to water the grove behind the temple of Zeus Philios, which lay inside the temenos (Paus. viii. 21, 4t-5). Unfortunately, however, only twenty yards of the pipe remain; after that it is cut into by Byzantine walls at either end, and does not reappear.

Other inscriptions found at Megalopolis this year are:

(1) Tiles picked up in the Stoa Philippeios.

IAIT3
$\Delta$ YO

Nothing is known of any Hestia worship in Megalopolis. 
THE DEVELOPMENT OF THE PLAN OF THE THERSILION. 337

(2) Tiles found in the building S.W. of the Stoa Philippeios.

\section{EAAT}

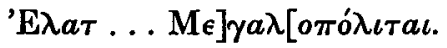

ГAA

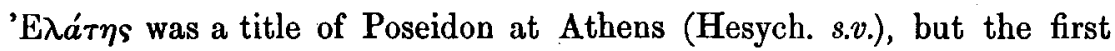
line of the inscription may be only a man's name.

$$
\begin{aligned}
& \text { OMI } \\
& \Pi 0 \wedge \text { A }
\end{aligned}
$$

Either this might be the date of the office of some Polybius, or the tile might come from the building near the temenos of Zeus Lykaios, where a statue of Polybius stood (Paus. viii. 30, 8).

\section{$A \Sigma K \wedge A \Pi I C$}

A statue of Asclepius stood in the neighbouring temenos of the great goddesses $(I d .31,1)$.

(3) Tile found ou the hill marked 7 in Mr. Loring's plan.

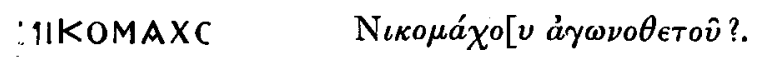

(4) The torso of a Herm-like statue of Poseidon, found near the spot marked 60 on Mr. Loring's plan. The inscription is on the cross-piece of a trident, which decorates the front of the statue.

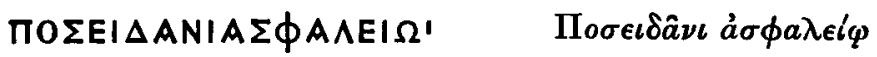

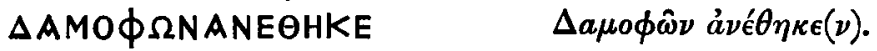

For the epithet of $\dot{a} \sigma \phi a ́ \lambda \epsilon \iota 0 s$ ef. Paus. iii. 11, 9, vii. 21, 7; Strabo, i. p. 57; Opp. Hal. v. 681 ; Ar. Ach. 682 and Schol.; Plut. Thes. 36 ; C.I.G. $2347 \mathrm{~h}$ and 4443 .

A. G. Bather. 